\title{
COX-2 Inhibition Reduces Brucella Bacterial Burden in Draining Lymph Nodes
}

\author{
Aurélie Gagnaire ${ }^{1}$, Laurent Gorvel2, Alexia Papadopoulos' ${ }^{1}$ Kristine Von Bargen", \\ Jean-Louis Mège ${ }^{3}$ and Jean-Pierre Gorvel ${ }^{\text {* }}$ *
}

' Aix Marseille Univ, CNRS, INSERM, CIML, Centre d'Immunologie de Marseille-Luminy, Marseille, France, ${ }^{2}$ Department of Pathology and Immunology, Washington University School of Medicine, St. Louis, MO, USA, ${ }^{3}$ Aix Marseille Univ, INSERM, CNRS, IRD, URMITE, Marseille, France

\section{OPEN ACCESS}

Edited by:

Axel Cloeckaert,

French National Institute for Agricultural Research (INRA), France

Reviewed by:

Gregory T. Robertson, Colorado State University, USA

Diego J. Comerci,

Universidad Nacional de San Martín

(CONICET), Argentina

Jean Celli,

Washington State University, USA

*Correspondence:

Jean-Pierre Gorvel

gorvel@ciml.univ-mrs.fr

Specialty section:

This article was submitted to

Infectious Diseases,

a section of the journal

Frontiers in Microbiology

Received: 13 October 2016 Accepted: 28 November 2016

Published: 12 December 2016

Citation:

Gagnaire A, Gorvel L, Papadopoulos A, Von Bargen $K$, Mège J-L and Gorvel J-P (2016) COX-2 Inhibition Reduces Brucella Bacterial Burden in Draining Lymph Nodes. Front. Microbiol. 7:1987. doi: 10.3389/fmicb.2016.01987
Brucella is a Gram-negative facultative intracellular bacterium responsible for a chronic disease known as brucellosis, the most widespread re-emerging zoonosis worldwide. Establishment of a Th1-mediated immune response characterized by the production of IL-12 and IFN $\gamma$ is essential to control the disease. Leukotrienes derived from arachidonic acid (AA) metabolism are known to negatively regulate a protective Th1 immune response against bacterial infections. Here, using genomics approaches we demonstrate that Brucella abortus strongly stimulates the prostaglandin (PG) pathway in dendritic cells (DC). We also show an induction of AA production by infected cells. This correlates with the expression of Ptgs2, a gene encoding the downstream cyclooxygenase-2 (COX-2) enzyme in infected DC. By comparing different infection routes (oral, intradermal, intranasal and conjunctival), we identified the intradermal inoculation route as the more potent in inducing Ptgs2 expression but also in inducing a local inflammatory response in the draining cervical lymph nodes (CLN). NS-398, a specific inhibitor of COX-2 enzymatic activity decreased B. melitensis burden in the CLN after intradermal infection. This effect was accompanied by a decrease of //10 and a concomitant increase of Ifng expression. Altogether, these results suggest that Brucella has evolved to take advantage of the PG pathway in the harsh environment of the CLN in order to persist and subvert immune responses. This work also proposes that novel strategies to control brucellosis may include the use of COX-2 inhibitors.

\section{Keywords: Brucella, COX-2, dendritic cells, intradermal infection, prostaglandins}

Abbreviations: 5-LO, 5-Lipoxygenase; AA, Arachidonic Acid; BMDC, Bone marrow-derived dendritic cell; Ccl2, C-Cchemokine ligand 2; Ccr7, C-C-chemokine receptor 7; CFU, Colony forming units; CLN, Cervical lymph nodes; COX-2, Cyclooxygenase-2; DC, Dendritic cells; DMSO, Dimethyl sulfoxide; EP, Prostaglandin E receptor; Foxp3, Forkhead box 3. GM-CSF, Granulocyte macrophage colony-stimulating factor; Gzmb, Granzyme B; IFN, Interferon; IL, Interleukin; LPS, Lipopolysaccharide; moDC, Monocyte derived dendritic cell; MOI, Multiplicity of infection; $\mathrm{NOS}_{2}$, Nitric oxide synthase 2; NS-398, N-[2- (cyclohexyloxy)-4-nitrophenyl]-methanesulfonamide; PBMC, Peripheral blood mononuclear cells; PG, Prostaglandins; PTGDS, Prostaglandin D synthase; PTGER, Prostaglandin E receptor; Ptgs2, Prostaglandin-endoperoxide synthase 2; Th1, T helper 1; TLR, Toll-like receptor; TNF- $\alpha$, Tumor Necrosis Factor $\alpha$; TSA, Tryptic Soy Agar; TSB, Tryptic Soy Broth. 


\section{INTRODUCTION}

Brucellosis is a disease caused by a Gram-negative facultative intracellular bacterium belonging to the genus Brucella. It is the most widespread re-emerging zoonosis worldwide affecting more than half a million people each year (Seleem et al., 2010). Brucella affects a wide range of land and aquatic mammals including humans and livestock. Animals are Brucella primary hosts in which the bacterium has a particular tropism for the reproductive system, often leading to spontaneous abortion and sterility responsible for severe economic losses (Pappas, 2010). Brucella can be transmitted to humans in close contact with infected animals mostly by ingestion of contaminated food or inhalation of aerosolized contaminated particles (Moreno, 2014). The Brucella species presenting the most important zoonotic potential for humans are B. melitensis, B. abortus, B. suis, and B. canis (Moreno, 2014). In human, the disease is characterized by an acute phase, which mainly manifests itself by asthenia, recurrent undulant fever and influenza-like symptoms. If the disease is not cured, it can evolve into chronic brucellosis, which may result in serious complications such as endocarditis or neurobrucellosis (Franco et al., 2007; Dean et al., 2012). Currently, there is no effective vaccine to prevent the disease in human highlighting the importance to understand the physiopathology of the disease.

To establish a persistent infection, Brucella behaves as a stealthy pathogen (Barquero-Calvo et al., 2007), using various strategies to modulate the host immune response. For instance, its unusual LPS plays a central role showing a low endotoxicity and being poorly recognized by Toll-like-receptor 4 (TLR4) (Lapaque et al., 2005; Lapaque et al., 2009; Conde-Álvarez et al., 2012). Brucella can also modulate the protective Th1 immune response characterized by the secretion of pro-inflammatory cytokines such as IL- $1 \beta$, IFN $\gamma$, TNF- $\alpha$, or IL-12 (Zhan and Cheers, 1995; Zhan et al., 1996; Martirosyan et al., 2011) by inducing an early IL-10 secretion orchestrated by CD $4^{+} \mathrm{CD} 25^{+}$ T cells (Xavier et al., 2013).

It has also been shown that $B$. abortus can activate the 5LO responsible for the synthesis of leukotrienes derived from AA (Fahel et al., 2015). The 5-LO activity impacts on proinflammatory cytokine secretion including IL-12 and IFN $\gamma$ in vivo (Fahel et al., 2015). Thus, 5-LO seems to function as a negative regulator of the protective Th1 response during mice infection with $B$. abortus. However, AA can be metabolized by different enzymes including the COX also known as Ptgs (Harizi et al., 2008). COX enzymes are responsible for the rate-limiting step in the biosynthesis of PG and other prostanoids among them thromboxanes and prostacyclins (Figure 1). Three known isoforms of COX have been identified so far: COX-1, COX-2 and COX-3 whose physiological function is not yet fully elucidated (Chandrasekharan et al., 2002; Chandrasekharan and Simmons, 2004). The constitutively and ubiquitously expressed COX-1 isoform is involved in basal and constitutive PG production. On the contrary, COX-2 is expressed at very low levels and is highly inducible following pro-inflammatory stimuli such as cytokines or endotoxins. COX-2 converts AA into prostaglandin $\mathrm{H}_{2}\left(\mathrm{PGH}_{2}\right)$, which is then converted into prostaglandin $\mathrm{D}_{2}$, prostaglandin $\mathrm{E}_{2}\left(\mathrm{PGE}_{2}\right)$, prostacyclins, or thromboxane $\mathrm{A}_{2}$ depending on cell specific enzymes expression (Figure 1). The context as well as the panel of PG receptors will define the pro- or anti-inflammatory action of these lipid mediators. Thus, PG have immunomodulatory traits that can worsen or improve bacterial clearance. This dual activity is observed during Salmonella Typhimurium infection in mice. Indeed, COX-2 inhibition during the acute stage of the disease increases bacterial load whereas at later stage it enhances mouse survival (Bowman and Bost, 2004). A similar pattern is observed in mice infected with Mycobacterium tuberculosis (Rangel Moreno et al., 2002).

Cyclooxygenase- 2 has been shown to have different outcomes during several bacterial and viral infections (Steer and Corbett, 2003; Agard et al., 2013) but little is known about its role during Brucella infection. Some studies have reported the impact of B. abortus and B. melitensis LPS on COX-2 expression in monocytes (López-Urrutia et al., 2001). Both smooth-LPS (SLPS) were found to induce COX-2 expression in THP-1 cell line and rat-peritoneal macrophages in a dose-dependent manner. $\mathrm{PGE}_{2}$ synthesis and its impact in bovine PBMC infected with live and $\gamma$-irradiated $B$. abortus have also been assessed showing that IL- 2 and IFN $\gamma$ suppression was independent on COX-1 and COX-2 (Stevens and Olsen, 1994) but these in vitro studies were not confirmed in vivo.

The aim of our study is to determine whether COX-2 is involved in protection against Brucella infection or exacerbation of the Brucella burden. We have investigated the ability of $B$. abortus to stimulate the AA-COX-2 pathway in infected human moDC and in mouse GM-CSF BMDC and studied the impact of COX-2 inhibition in vivo after intradermal infection with $B$. melitensis. Here, we demonstrate that $B$. abortus enhances AA production in human moDC and Ptgs 2 expression both in human moDC and murine GM-CSF BMDC. The comparison of different inoculation routes allowed us to identify the intradermal route as the more potent to induce Ptgs 2 expression and local inflammatory response in CLN. COX-2 inhibition decreases the bacterial burden in CLN characterized by a decrease of Il10 and an increase of Ifng expression. Thus, further development of COX-2 inhibitors may represent a novel therapeutic strategy against Brucella.

\section{MATERIALS AND METHODS}

\section{Ethics Statement}

This study was carried out in strict accordance with the guidelines of the Council of the European Union (Directive $86 / 609 / \mathrm{EEC}$ ) regarding the protection of animals used for experimental and other scientific purposes. The experimental protocol was approved by the institutional animal care and use committee of the Aix-Marseille University ( $\mathrm{N}^{\circ}$ 87-848, October 19, 1987, Paris, modified by Decree 2001-464 and Decree 2001-131 relative to European Convention, EEC directive 86/609). All experiments were done in accordance with French and European guidelines for animal care. Blood was obtained from the Etablissement Français du Sang. As it is a commercial product, the Ethics Committee agreement is not required. 


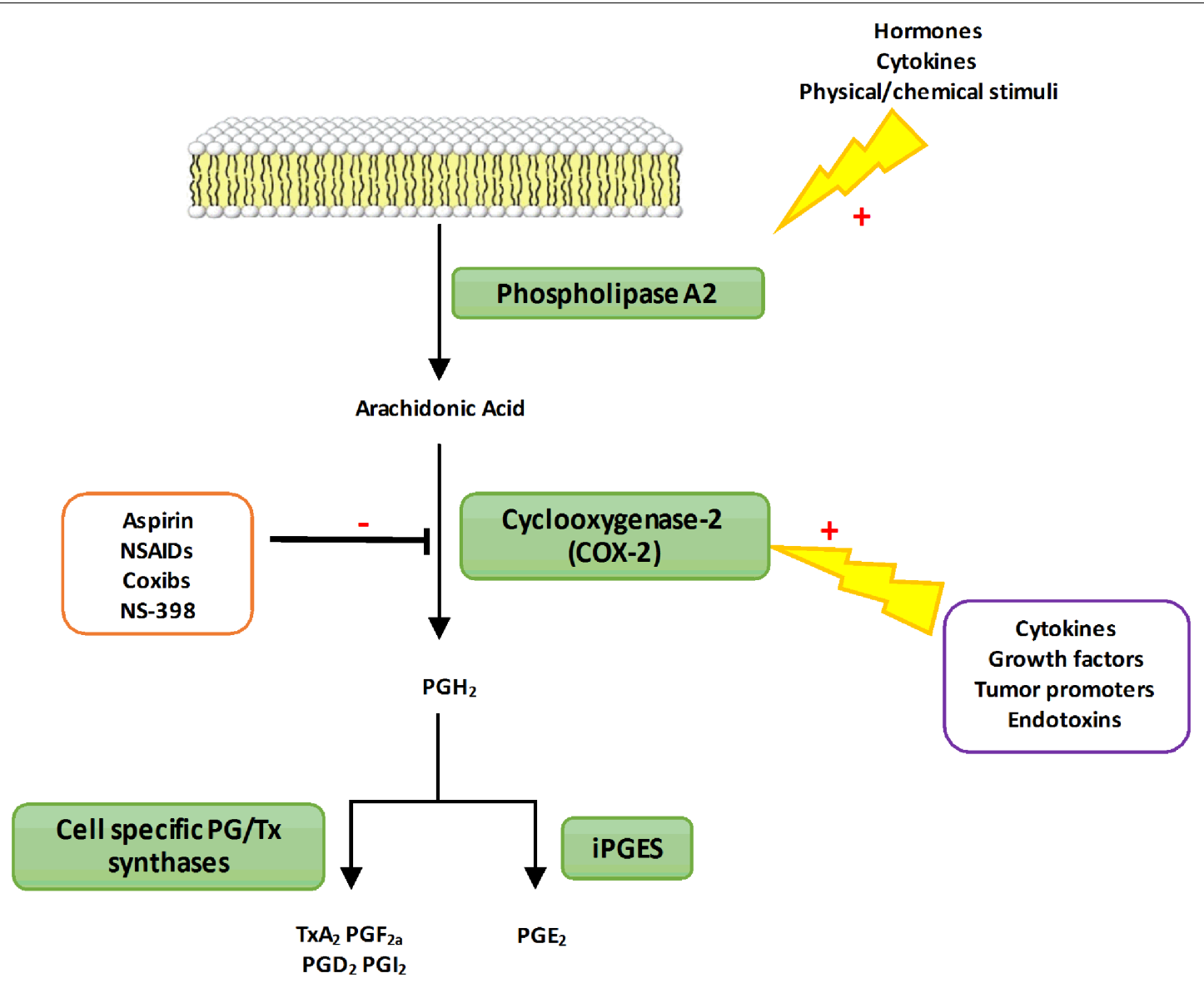

FIGURE 1 | The PGs biosynthetic pathway. In response to different types of stimuli (hormones or cytokines), phospholipase A2 is activated to produce AA from membrane phospholipids. Free AA can be metabolized by the COX-2 enzyme to produce $\mathrm{PGs}_{2}\left(\mathrm{PGH}_{2}\right)$. $\mathrm{PGH}_{2}$ is then converted into prostanoids through the action of various synthases differentially expressed in cells. PG, Prostaglandins; TX, Thromboxane; NSAIDs, Nonsteroidal anti-inflammatory drugs; COX-2,

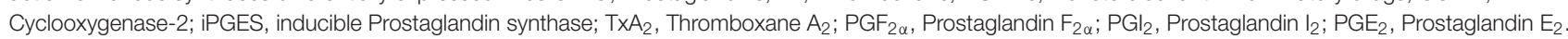

\section{Mice and Bacteria}

Six to eight weeks old females C57BL/6 (Charles River Laboratories) were maintained under pathogen-free conditions and fed sterile food and water ad libitum. All infections were performed under Animal Biosafety Level 3 facility.

\section{Bacterial Strains}

Orentia tsutsugamushi strain Kato (CSUR R163) (gift from Dr. Jean-Louis Mège, URMITE, Marseille, France) was propagated in L929 cells (ATCC), as previously described (Barry et al., 2012). Briefly, highly infected cells were sonicated, or lysed using glass beads for $O$. tsutsugamushi, and centrifuged at $500 \times g$ for $10 \mathrm{~min}$ to remove cell debris. Supernatants were collected and centrifuged at $10,000 \times g$ for $10 \mathrm{~min}$ to pellet the bacteria. Live bacteria were quantified using infected cellcounting units. Coxiella burnetii organisms (RSA493 Nile Mile strain) (gift from Dr. Jean-Louis Mège, URMITE, Marseille, France) were obtained by passage in BALB/c mice (Charles River Laboratories) and culture in L929 cells. The concentration of organisms was determined by immunofluorescence using specific antibodies and/or PCR using known concentrations of bacterial DNA. The quantification of organisms was performed as previously described (Barry et al., 2012). Bacterial viability was assessed using the LIVE/DEAD Bac Light bacterial viability kit (Invitrogen). Brucella abortus strain 2308 and Brucella melitensis strain 16M (gift from Dr Ignacio Moriyon, University of Pamplona, Spain) were grown on TSA (Sigma-Aldrich) at $37^{\circ} \mathrm{C}$ for 7 days, as previously described (Pizarro-Cerdá et al., 1998). The Twist-Marseille (CNCM I-2202) strain of Tropheryma whipplei (gift from Dr. Jean-Louis Mège, URMITE, Marseille, France), a bacterium known to live in macrophages, was cultured in HEL cells and purified. Quantification of inocula was performed by measuring the percentage of infected cells by immunofluorescence, as previously described (Gorvel et al., 2010).

\section{Isolation of Human moDC}

Peripheral blood mononuclear cells from buffy coats were recovered from the Ficoll-Hypaque (GE healthcare) interface after centrifugation at $700 \times g$ for $20 \mathrm{~min}$. Monocytes and $\mathrm{T}$ lymphocytes were isolated from PBMCs using 
magnetic beads coupled to antibodies specific for CD14 and $\mathrm{CD} 3$, respectively, as described by the manufacturer (Miltenyi Biotec). The purity of the monocyte and T-cell preparations was assessed by flow cytometry and was greater than 98\%. Monocytes were then incubated in RPMI 1640 (Gibco) containing $20 \mathrm{mM}$ HEPES, $2 \mathrm{mM}$ glutamine, $10 \%$ fetal calf serum (FCS) (Invitrogen), $0.1 \mathrm{ng} / \mathrm{mL} \mathrm{IL-4}$ and $1 \mathrm{ng} / \mathrm{mL}$ granulocyte-macrophage colony-stimulating factor (GM-CSF) (R\&D Systems) for 7 days to obtain moDC.

\section{In vitro Generation of BMDC}

Bone marrow-derived dendritic cells were prepared from 6 to 8 week-old females $\mathrm{C} 57 \mathrm{BL} / 6$ mice as previously described (Salcedo et al., 2008). Briefly, tibias and femurs were flushed with RPMI-5\%FCS (Eurobio)-50 $\mu \mathrm{M} \quad 2 \beta$-mercaptoethanol (Sigma-Aldrich) to extract bone marrow.

In order to generate GM-CSF-BMDC, $3.10^{6}$ cells per well were seeded onto 6-well plates in medium supplemented with supernatant of J558L GM-CSF producing cell line (gift from Dr. Philippe Pierre, Centre d'Immunologie de Marseille-Luminy, Marseille, France). The medium was changed at day 2.5 .

\section{In vitro Infection Assays}

GM-CSF-DC were infected with $B$. abortus smooth virulent strain 2308 using a MOI of 30:1. Bacteria were centrifuged onto cells at $400 \times g$ for $10 \mathrm{~min}$ at $4^{\circ} \mathrm{C}$. Then, cells were incubated for $30 \mathrm{~min}$ at $37^{\circ} \mathrm{C}$ with $5 \% \mathrm{CO}_{2}$. After two washes with medium, cells were incubated for one hour with medium containing antibiotic [gentamicin (Sigma-Aldrich) at $50 \mu \mathrm{g} / \mathrm{ml}$ ] in order to kill the extracellular bacteria. Thereafter, the antibiotic concentration was decreased at $10 \mu \mathrm{g} / \mathrm{ml}$ until the end of the infection time.

\section{In Vivo Bacterial Challenge}

Brucella melitensis $16 \mathrm{M}$ with a chromosomal integration of DsRed was used in this study. B. melitensis were grown under shaking in TSB (Sigma-Aldrich) containing $25 \mu \mathrm{g} / \mathrm{ml}$ kanamycin (Sigma-Aldrich) at $200 \mathrm{rpm}$ for $16 \mathrm{~h}$ at $37^{\circ} \mathrm{C}$. Inocula were prepared by pelleting bacteria and by adjusting bacterial concentration in endotoxin free PBS (Gibco) to obtain the right concentration depending on the inoculation route. Oral infection was performed as previously described (von Bargen et al., 2014). Briefly, pelleted bacteria were re-suspended to previously heatsterilized 5\% milk and adjusted at respective MOI in 5\% milk (Scharlau). For all the other inoculation routes, mice were anesthetized with Ketamine/Xylazine (Virbac). For intranasal infection, the bacterial inoculum containing $10^{5} \mathrm{CFU}$ suspended in $35 \mu \mathrm{L}$ of endotoxin free PBS (Gibco) was applied onto mice nostril via pipet. For intradermal infection, the bacterial inoculum containing $10^{4} \mathrm{CFU}$ suspended in $10 \mu \mathrm{L}$ of endotoxin free PBS was injected into the ear pinna. For conjunctival infection, the bacterial inoculum containing $10^{9} \mathrm{CFU}$ suspended in $10 \mu \mathrm{L}$ was applied onto conjunctival surfaces $(5 \mu \mathrm{L}$ per eye). In some experiments, the selective COX-2 inhibitor NS398 (Cayman Chemicals) were administered by intraperitoneal injection $(15 \mathrm{mg} / \mathrm{kg})$ right after intradermal infection. A stock solution of NS-398 was prepared in DMSO (Sigma-Aldrich) and was diluted in PBS just prior to treatment to the right concentration in a 1:3 (DMSO:PBS) ratio for a total volume of $100 \mu \mathrm{L}$ per mouse or vehicle control (DMSO:PBS alone).

Treatments were repeated daily for 7 days. At 8 and 29 days post-infection mice were sacrificed by cervical dislocation. Immediately after sacrifice, CLN (including mandibular, accessory mandibular, and superficial parotid lymph nodes referred here as CLN; Van den Broeck et al., 2006) and spleens were collected, weighted, and proceeded for bacterial count and RNA extraction.

\section{Analysis of Organ Bacterial Burden}

Spleens and CLN were removed and homogenized in Triton X-100 (Sigma-Aldrich) 0.1\%. Serial dilutions were performed in PBS, and plated in triplicate onto TSA agar. CFU were enumerated after $3-4$ days of culturing at $37^{\circ} \mathrm{C}$.

\section{Microarrays}

Monocyte derived dendritic cells $\left(5.10^{6}\right.$ cells per well) were plated in 6-well plates and stimulated or not with B. abortus (MOI of 300:1) for 6 hours, and total RNA was then extracted using the RNeasy minikit (Qiagen) and DNase treatment. This study utilized the 4X44k Human Whole Genome microarrays (Agilent Technologies), representing 44,000 probes. Reverse transcription, samples labeling, and hybridization were performed according to the protocols specified by the manufacturer (One-Color Microarray-Based Gene Expression Analysis). Three samples per experimental condition were included in the analysis. The slides were scanned at a $2-\mathrm{mm}$ resolution with a G2505C DNA microarray scanner (Agilent Technologies).

\section{RNA Extraction, RT, and q-PCR}

Total RNAs from infected GM-CSF-BMDC were extracted using RNeasy Micro Kit (Qiagen) following manufacturer's instructions. CLN were stabilized in RNAlater (Qiagen) immediately after sampling. Organs were homogenized in RLT buffer (Qiagen) and then extracted using RNeasy Micro Kit (Qiagen) following manufacturer's instructions. cDNAs were obtained by using Quantitech Reverse Transcription Kit (Qiagen) following manufacturer's instructions using $300 \mathrm{ng}$ of RNA as a matrix. qPCR were conducted using a 7500 Fast-Real-time PCR (Applied Biosystem) with SYBER Green (Takara) following manufacturer's instructions. HPRT was used as housekeeping gene to determine $\Delta \mathrm{Ct}$. Fold change compared to base line expression in uninfected cells, or control mice was determined using $2^{-\Delta \Delta C t}$ method where $\Delta \Delta \mathrm{Ct}=\left(\mathrm{Ct}_{\text {target }}-\mathrm{Ct}_{\mathrm{HPRT}}\right)_{\text {infected }}-\left(\mathrm{Ct}_{\text {target }}-\mathrm{Ct}_{\mathrm{HPRT}}\right)_{\text {non-infected }}$ as previously described (Papadopoulos et al., 2016). mRNAs whose expression level was twice as high compared to control were considered as significantly up-regulated. Primers used in this study are listed in Table $\mathbf{1 .}$

\section{Arachidonic Acid Quantification}

Monocyte derived dendritic cells were stimulated by bacterial pathogens (MOI 50:1 for T. whipplei or 20:1 for others) or 
TABLE 1 | Primers used for analysis of gene expression upon infection.

\begin{tabular}{|c|c|c|}
\hline Genes & Forward Primers & Reverse Primers \\
\hline HPRT & AGCCCTCTGTGTGCTCAAGG & CTGATAAAATCTACAGTCATAGGAATGGA \\
\hline Ifng & TCAAGTGGCATAGATGTGGAAGAA & TGGCTCTGCAGGATाTCATG \\
\hline $1 / 6$ & GAGGATACCACTCCCAACAGACC & AAGTGCATCATCGTTGTTCATACA \\
\hline Gzmb & ATCAAGGATCAGCAGCCTGA & CATGATGTCATTGGAGAATGTCT \\
\hline Nos2 & CAGCTGGGCTGTACAAACCTT & CATTGGAAGTGAAGCGTTCG \\
\hline Ptgs2 (Cox2) & АССTCTGCGATGCTCTTCC & TCATACATTCCCCACGGTाT \\
\hline $\mathrm{Ccl} 2$ & GCCTGCTGTTCACAGTTGC & ATTGGGATCATCTTGCTGGT \\
\hline Ccr7 & GTGGTGGCTCTCCTTGTCAT & GAAGCACACCGACTCGTACA \\
\hline $1 / 10$ & GGTTGCCAAGCCTTATCGGA & ACCTGCTCCACTGCCTTGCT \\
\hline Foxp3 & AGGAGCCGCAAGCTAAAAGC & TGCCTTCGTGCCCACTGT \\
\hline Tnf & CATCTTCTCAAAATTCGAGTGACAA & TGGGAGTAGACAAGGTACAACCC \\
\hline 114 & ACTCTICGGGCTITCGAT & TTGCATGATGCTCTIAGGC \\
\hline
\end{tabular}

Escherichia coli LPS (Sigma-Aldrich) (1 $\mu \mathrm{g} / \mathrm{ml})$ for $16 \mathrm{~h}$, suspended in $0.3 \mathrm{~mL}$ of cold methanol $(\mathrm{MeOH})$. Fatty acid methyl esters (FAME) extraction was performed as previously described (Schutter and Dick, 2000; Ecker et al., 2012), $15 \mu \mathrm{L}$ of $\mathrm{MeOH} /$ Deuterium-labeled eicosanoids (LTB4-d4 and 5-HETE$\mathrm{d} 8,400 \mathrm{ng} / \mathrm{ml}$ ) standard solution were added to $0.2 \mathrm{ml}$ of homogenate. After centrifugation, supernatants were diluted in $10 \mathrm{~mL}$ of hydrochloric acid $(\mathrm{HCl}) 0.02 \mathrm{M}$ and submitted to solid-phase extraction on C18 cartridge (Macherey Nagel). After complete loading, columns were washed, dried and lipid mediators were eluted in methyl formate (MeFor). Solvent was evaporated under $\mathrm{N} 2$ and samples were dissolved within $30 \mu \mathrm{L}$ $\mathrm{MeOH}$ and stored at $-80^{\circ} \mathrm{C}$.

For AA quantification, $0.1 \mathrm{ml}$ of homogenates were extracted in dichloromethane/methanol/water, in the presence of $2 \mu \mathrm{g}$ glyceryl triheptadecanoate (Sigma-Aldrich) and hydrolyzed in potassium hydroxyde $(\mathrm{KOH})(0.5 \mathrm{M}$ in $\mathrm{MeOH})$ at $50^{\circ} \mathrm{C}$ for $30 \mathrm{~min}$. Lipids were transmethylated in $14 \%$ boron trifluoride $\mathrm{MeOH}$ solution (Sigma-Aldrich) and hexane at $80^{\circ} \mathrm{C}$ for $1 \mathrm{~h}$. FAME were extracted with hexane, dried and dissolved in ethyl acetate.

Fatty acid methyl esters were analyzed by gas-liquid chromatography as previously described (Lepage and Roy, 1986) on a Clarus 600 Perkin Elmer system using Famewax RESTEK fused silica capillary columns $(30 \mathrm{~m} \times 0.32 \mathrm{~mm}$ i.d, $0.25 \mu \mathrm{m}$ film thickness). Oven temperature was programmed from $110^{\circ} \mathrm{C}$ to $220^{\circ} \mathrm{C}$ at a rate of $2^{\circ} \mathrm{C}$ per min and the carrier gas was hydrogen ( 0.5 bar). The injector and the detector were at $225^{\circ} \mathrm{C}$ and $245^{\circ} \mathrm{C}$, respectively. LC-MS/MS analysis was performed on UHPLC system (Agilent LC1290 Infinity) coupled to Agilent 6460 triple quadrupole MS (Agilent Technologies) equipped with electrospray ionization source. Separation was done at $40^{\circ} \mathrm{C}$ on a Zorbax SB-C18 column (2.1 mm, $50 \mathrm{~mm}, 1.8 \mu \mathrm{m}$ ) (Agilent Technologies). The mobile phases were, respectively water, ACN and FA (75/25/0.1) (A) and ACN, FA (100/0.1) (B). The linear gradient was as follows: $0 \% \mathrm{~B}$ at $0 \mathrm{~min}, 85 \% \mathrm{~B}$ at $8.5 \mathrm{~min}, 100 \%$ $\mathrm{B}$ at $9.5 \mathrm{~min}, 100 \% \mathrm{~B}$ at $10.5 \mathrm{~min}$, and $0 \% \mathrm{~B}$ at $12 \mathrm{~min}$. The flow rate was $0.35 \mathrm{~mL} / \mathrm{min}$. The autosampler was set at $5^{\circ} \mathrm{C}$ and the injection volume was $5 \mu \mathrm{L}$. Electrospray ionization was performed in negative ion mode with a spray voltage fixed at $-3500 \mathrm{~V}$. After optimization, source conditions were as follows: source temperature was $325^{\circ} \mathrm{C}$, nebulizer gas (nitrogen) flow rate was $10 \mathrm{~L} / \mathrm{min}$, sheath gas temperature was $400^{\circ} \mathrm{C}$ and sheath gas (nitrogen) flow rate was $12 \mathrm{~L} / \mathrm{min}$. Analyses were acquired in multiple reaction mode (MRM) using nitrogen as collision gas. For each compound the conditions of separation: retention time in minute (RT), and of quantification were defined: specific Q1/Q3 transition (T) fragmentor (F), and collision energy (CE). Thus, optimized parameters were as follows: LTB4 (RT: $4.32 \mathrm{~min}$, T: 335/195, F: 115 V; CE: 4 V), LTB4-d4 (RT: 4.31 min, T: 339/197, F: $120 \mathrm{~V}$, CE: $6 \mathrm{~V}$ ). Peak detection, integration and quantitative analysis were performed using Mass Hunter Quantitative analysis software (Agilent Technologies).

\section{Statistical Analysis}

The results are expressed as mean $\pm \mathrm{SD}$ and statistical significance was assessed using the unpaired, two-tailed Student's $t$-test or by analysis of variance (ANOVA) followed by Tukey's multiple comparison test provided by GraphPad Prism software when more than two conditions were analyzed simultaneously. $p$ values over 0.05 were not considered as significant.

\section{RESULTS}

\section{B. abortus Infection of moDC and GMCSF-BMDC Stimulates AA-Cyclooxygenase Pathway}

We first measured the AA concentration in B. abortus infected moDC culture supernatants at $16 \mathrm{~h}$ post-infection. In parallel, other intracellular bacteria (T. whipplei, C. burnetii, O. tsutsugamushi) were tested. Only B. abortus and $O$. tsutsugamushi induced a significant AA production compared to non-stimulated moDC (Figure 2A).

AA can be metabolized by the COX pathway (Harizi et al., 2008). Thus, to determine the impact of B. abortus on this pathway, we analyzed the transcriptional profile of several key genes involved in the PG and leukotriene pathways in infected cells (Figure 2B). Compared to unstimulated cells, infected human moDC strongly expressed PTGS2 
A

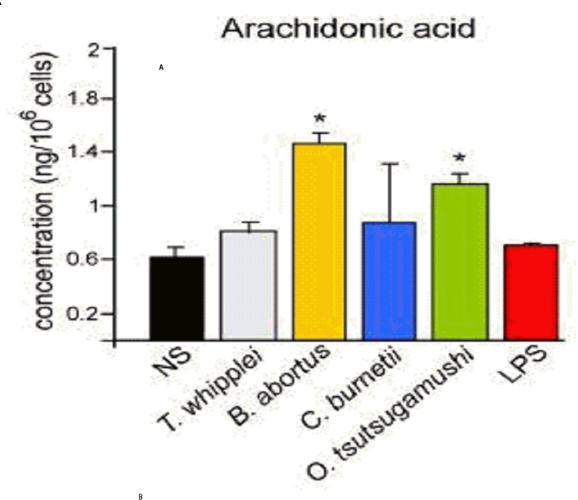

C

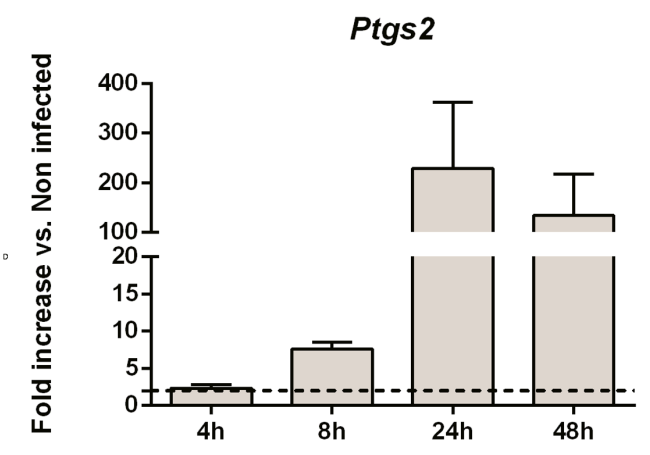

B

Prostaglandins pathway

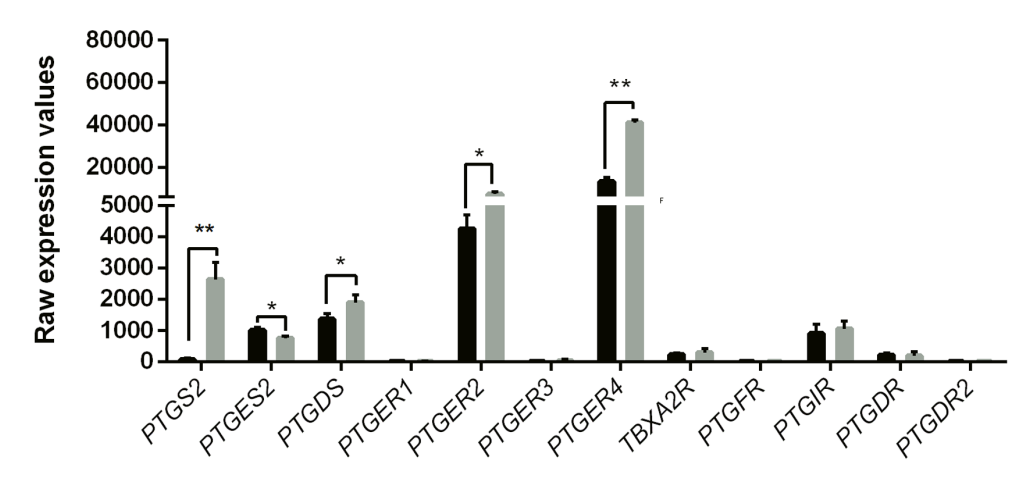

Leukotrienes pathway

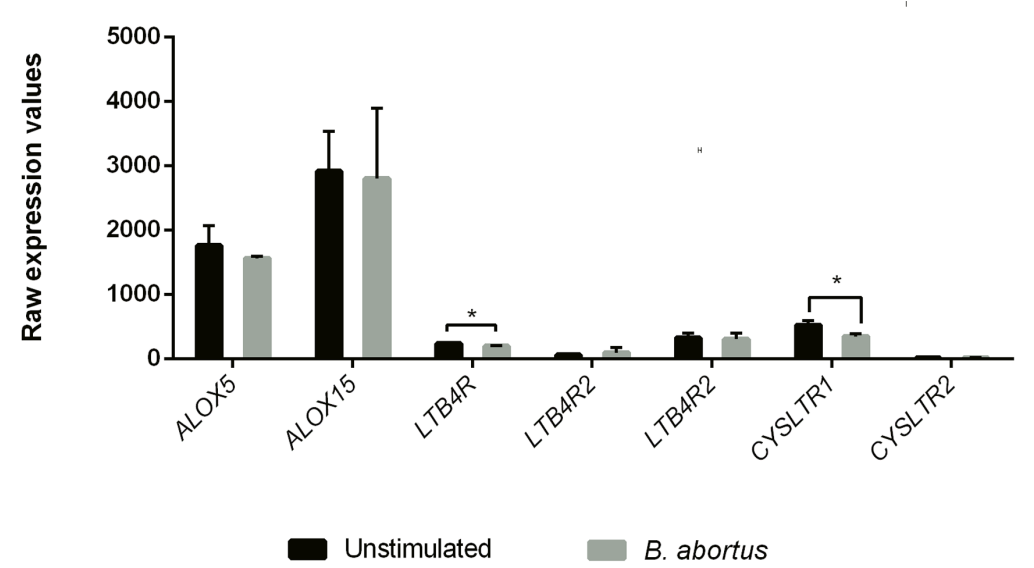

FIGURE 2 | Prostaglandins pathway highlights induced AA metabolism in human moDC and mice GM-CSF BMDC upon Brucella abortus infection. (A) moDC were stimulated or not (NS) during $16 \mathrm{~h}$ with Tropheryma whipplei (30:1), B. abortus (20:1), Coxiella burnetii (20:1), Orentia tsutsugamushi (20:1), or Escherichia coli LPS $(1 \mu \mathrm{g} / \mathrm{mL})$ and then treated for AA dosage. The AA concentration after infection was compared to unstimulated condition using unpaired, two-tail Student's $t$-test $(* p<0.05)$ (Results of three independent experiments). Results are given as mean \pm SD. (B) Transcriptomic analysis. moDC were stimulated or not with $B$. abortus, for $6 \mathrm{~h}$. RNA was extracted, and a microarray was performed. Statistical analysis was performed using unpaired, two-tail Student's $t$-test $(* p<0.05 ; * *<0.005 ; * * * p<0.001)$ and results are given as mean \pm SD (Results of three independent experiments). (C) GMCSF BMDC from C57BL/6 mice were infected with $B$. abortus 2308 (30:1). At 4, 8, 24, and 48 h post-infection, cells were recovered and RNA was extracted. Gene expression is represented as a fold increases between non-infected and infected cells. Statistical analyses were performed by using the comparative CT Method ( $\Delta \Delta$ CT method) given by $2^{-\Delta \Delta C T}$. The dotted line represents a fold increase of 2, the statistical significant threshold in this method. Results are given as mean \pm SD (Results of three independent experiments). 
(33 times higher) and in a lesser extend PTGER2, PTGER4 and PTGDS (1,7, 3,1, and 1,3 times higher, respectively) (Figure 2B, upper panel). On the contrary, none of the genes involved in the leukotriene pathway were upregulated following Brucella infection (Figure 2B, lower panel).

We next investigated the expression of Ptgs 2 in murine GMCSF-derived DC at $4,8,24$, and 48 h post-infection. We observed that as in human DC, murine Ptsg2 mRNA level was strongly up regulated. Ptsg2 expression was time-dependent, reaching a peak at $24 \mathrm{~h}$ post-infection (229.4-fold up regulated compared to noninfected cells) (Figure 2C).

These results show that $B$. abortus infection is capable of stimulating the AA metabolic pathway and downstream PG pathway both in human and mice DC.

\section{Intradermal Infection Is Characterized by a Strong Ifng and Ptgs2 Signature}

We next investigated the involvement of the PTGS-2 pathway in vivo upon infection in mice. We have first compared three different Brucella strains (B. abortus 2308, B. melitensis 16M, and $B$. suis 1330) and their ability to colonize CLN at 8 and 15 days post-infection using the oral infection model we previously shown to induce a specific colonization of CLN (von Bargen et al., 2014). We avoided to use intraperitoneal inoculation since it is associated to systemic infection and recedes from Brucella physiological routes of infection or vaccination (Grilló et al., 2012). Although bacterial loads in CLN were very similar at any time point for all Brucella species (Supplementary Figure 1A), B. melitensis and B. suis induced a higher lymphadenopathy compared to B. abortus at 15 days post-infection suggesting an enhanced inflammatory response in the CLN (Supplementary Figure 1B). We then decided to continue this study with B. melitensis $16 \mathrm{M}$.

WT C57BL/6 mice were inoculated with $B$. melitensis by oral administration (with $10^{9}$ bacteria per mouse) as previously described (von Bargen et al., 2014) or by intranasal (with $10^{5}$ bacteria per mice), conjunctival $\left(10^{9}\right.$ bacteria per mice) or intradermal $\left(10^{4}\right.$ bacteria per mice) routes. Mice were sacrificed at 8 and 29 days post-infection and the weight and bacterial load of CLN and spleens were measured (Figures 3A,B).

At 8 days post-infection, the intradermal route was the only route capable of inducing lymphadenopathy compared to mocktreated mice and to other inoculation methods (Figure 3A, Left panel). No splenomegaly was observed at 8 days post-infection compared to mock-treated mice (Figure 3A, Right Panel). These results correlated with bacterial loads. CFU numbers in CLN were higher in mice infected intradermally compared to the other infection routes (Figure 3B, Left panel). However, spleens were poorly colonized as observed in all infection conditions (Figure 3B, Right panel). At 29 days post-infection, all inoculation routes resulted in lymphadenopathy and induced splenomegaly (Figure 3A). The increase in CLN and spleen weight was not associated with an increase in bacterial load (Figure 3B). This suggests the establishment of an inflammatory response in these organs.
We next investigated the local immune response induced by Brucella infection in the spleens and CLN by extracting mRNA at 8 and 29 days post-infection. Results were analyzed as a fold increase compared to their mock counterparts. No significant response was observed in the spleen for any infection routes (Supplementary Figure 2). On the contrary, a clear inflammatory response was observed in the CLN of mice infected intradermally from 8 days post-infection onwards (Figure 3C). This response led to a strong up-regulation of Ifng, Gzmb and Ptgs2 mRNAs (64, 18.6, and 30.8-fold, respectively) (Figure 3C). At 29 days post-infection, Ifng, Gzmb, and Il6 mRNA levels strongly decreased whereas a strong up-regulation of Ptgs 2 and in a lesser extent Nos2 and Ccl2 mRNA levels remained (Figure 3C). The inflammatory response was less pronounced using the other inoculation routes. Indeed, no significant changes between day 8 and 29 were observed in terms of mRNA expression levels except for conjunctival inoculation displaying an increase of Nos2 and $C c l 2$ mRNA levels (Fold change: 10.3 and 2.9, respectively) (Figure 3C).

In conclusion, the intradermal infection route is the most potent at inducing inflammatory genes expression and Ptgs2 seems to be a robust marker of Brucella intradermal infection compared to intranasal, conjunctival or oral infection routes. At 29 days post-infection following B. melitensis intradermal inoculation, the expression of Il6 was significantly higher compared to intranasal infection. Nos2 (compared to the oral and intranasal routes), Ptgs2 and $\mathrm{Ccl} 2$ genes (compared to all the other routes) were also increased (Figure 3C). Interestingly, no systemic response was observed in mice sera at any time independently from the inoculation route except for IFN- $\gamma$ after intradermal infection. However, low but significant amounts of TNF- $\alpha$ were detected in the sera of mice infected intradermally at 8 days post-infection (Supplementary Figure 3).

Overall, these results strongly suggest that in the CLN after intradermal infection a robust inflammatory response characterized by an Ifng and a Ptgs2 signature takes place.

\section{COX-2 Inhibition Reduces Bacterial Burden In vivo}

After having identified that the intradermal route was the more potent to induce Ptgs2 expression during B. melitensis infection, we evaluated in vivo the involvement of COX-2 during infection. WT C57BL/6 mice were challenged intradermally with B. melitensis $\left(10^{4}\right.$ bacteria per mice) and were given NS-398, a specific COX-2 inhibitor, or DMSO vehicle (mock control) by intraperitoneal administration daily for 7 days.

We first looked at CLN and spleen weights at 8 days post-infection. Independently of the treatment, infected mice presented a lymphadenopathy compared to uninfected mice. However, NS-398 treatment induced a decrease in CLN weight compared to non-treated infected mice (Figure 4A, Left panel). This effect was consistent with the anti-inflammatory properties of NS-398. No significant effect could be observed in the spleen (Figure 4A, Right panel). This response was accompanied by a decrease of CFU numbers in CLN in treated mice (Figure 4A, 
A

CLN

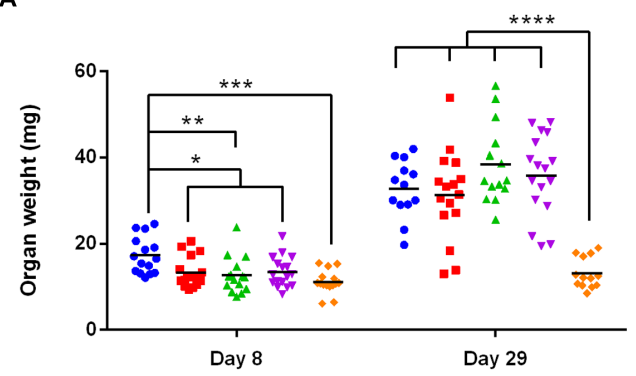

B

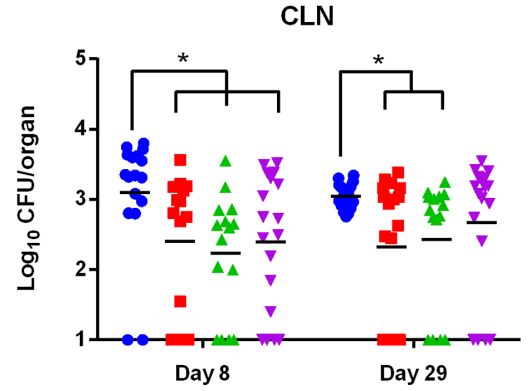

C

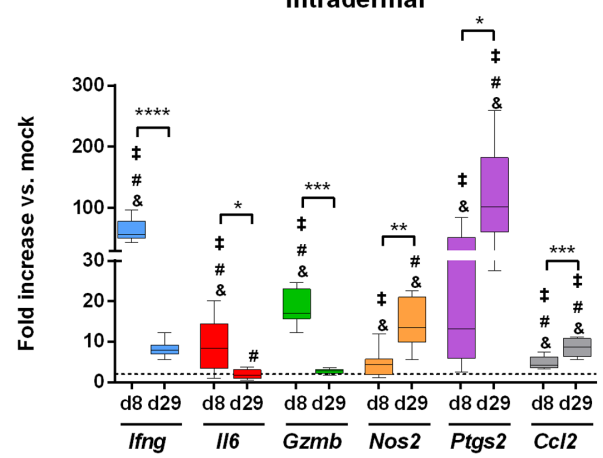

Oral

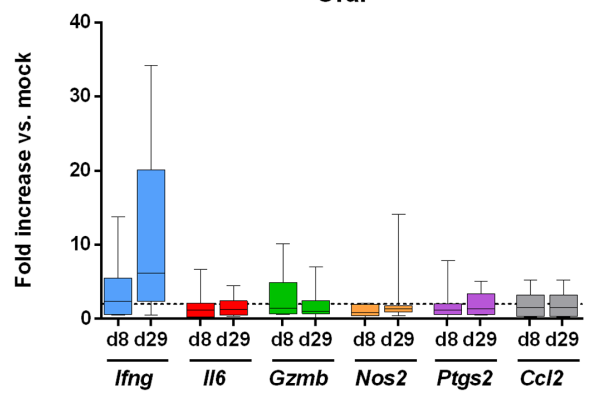

Spleen

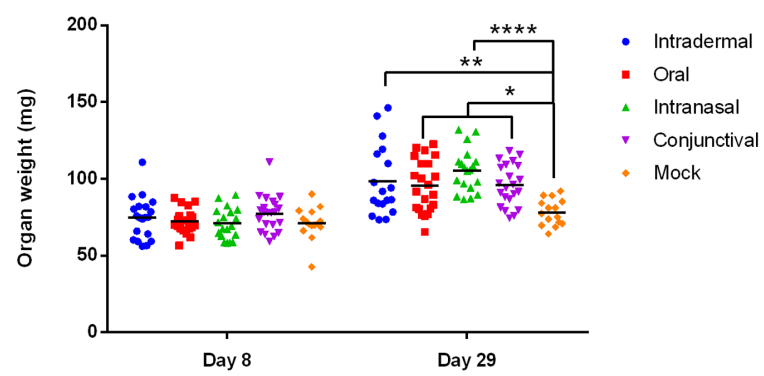

Spleen

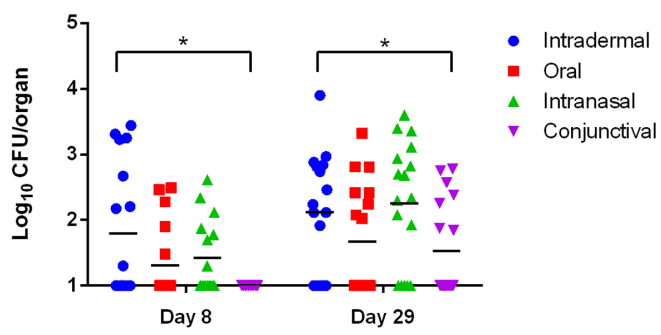

Conjunctival

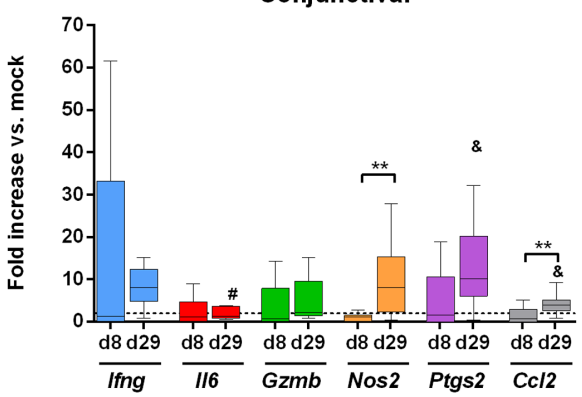

Intranasal

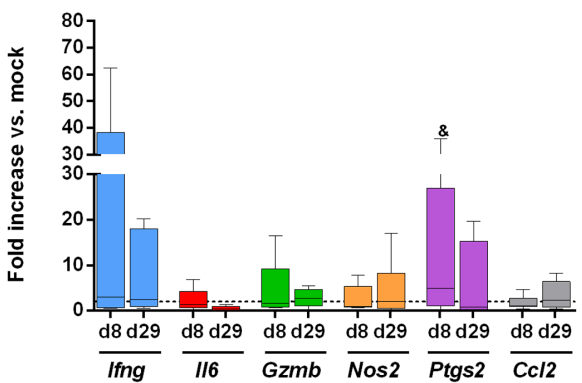

FIGURE 3 | The intradermal inoculation pathway induces a strong local inflammatory response in CLN. C57BL/6 mice ( $n=5$ per group) were infected using the routes of infection described in the methods section. At 8 and 29 days post-infection, mice were sacrificed and organs were weighed and analyzed for their bacterial loads by plating homogenates on nutrient agar. Data represent mean of CLN (Left panel) and spleen (Right panel) weight (A) or CFU per organ (B) from three independent experiments. Analysis significance was determined using ANOVA $\left({ }^{*} p<0.05 ;{ }^{* *} p<0.005 ;{ }^{* * *} p<0.001 ;{ }^{* * * *} p<0.0001\right)$. (C) C57BL/6 mice ( $n=5$ per group) were infected using different routes of infection as described in methods section. At 8 and 29 days post-infection, total RNA of the CLN was extracted and analyzed for inflammatory response gene expression by reverse transcription real-time PCR. Results are given as fold increase compared to the signal obtained for mock-infected mice. Statistical significance was determined using unpaired, two-tailed Student's $t$-test (Results of three independent experiments) $\left({ }^{*} p<0.05 ;{ }^{* *} p<0.005 ;{ }^{* * *} p<0.001 ;{ }^{* * * *} p<0.0001\right)$ and ${ }^{\&}$ significant compared to the oral route; ${ }^{*}$ significant compared to the intranasal route and ${ }^{*}$ significant compared to the conjunctival route using ANOVA. 


\section{CLN}

\section{Spleen}
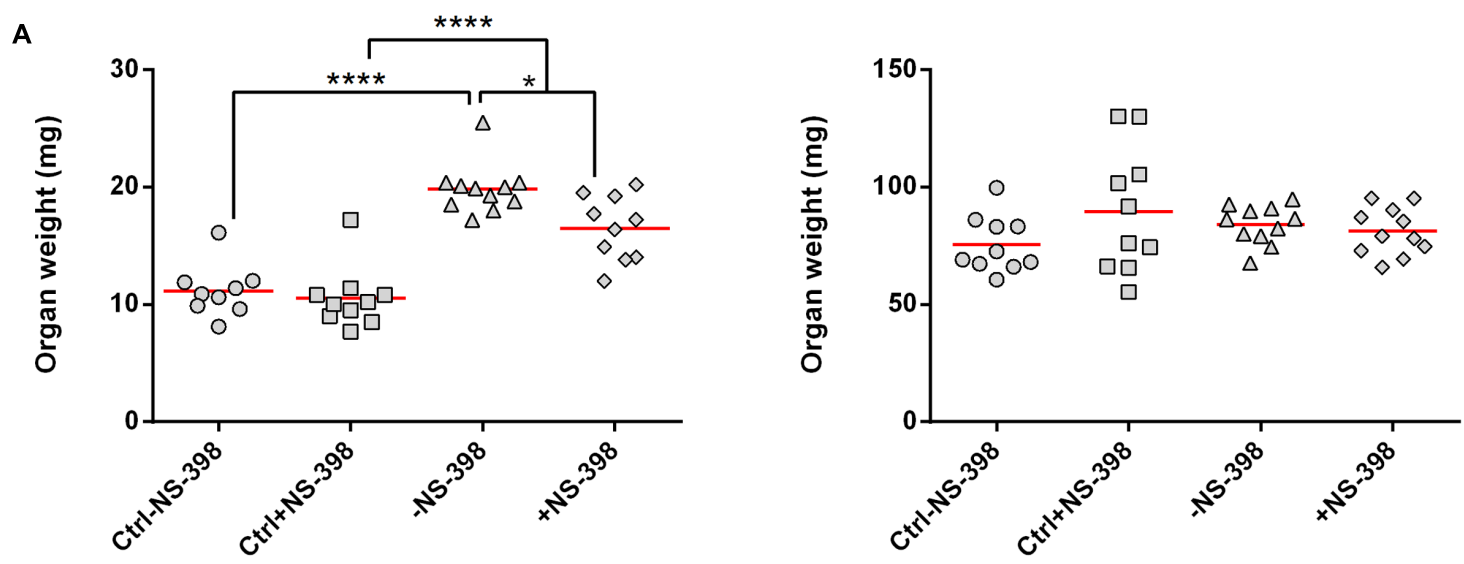

B

CLN
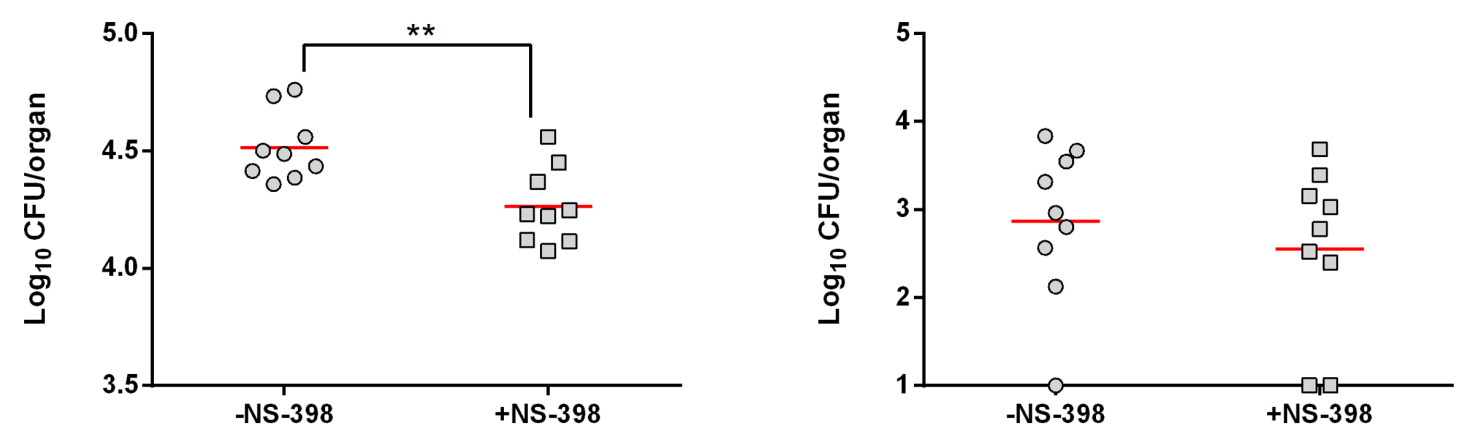

C

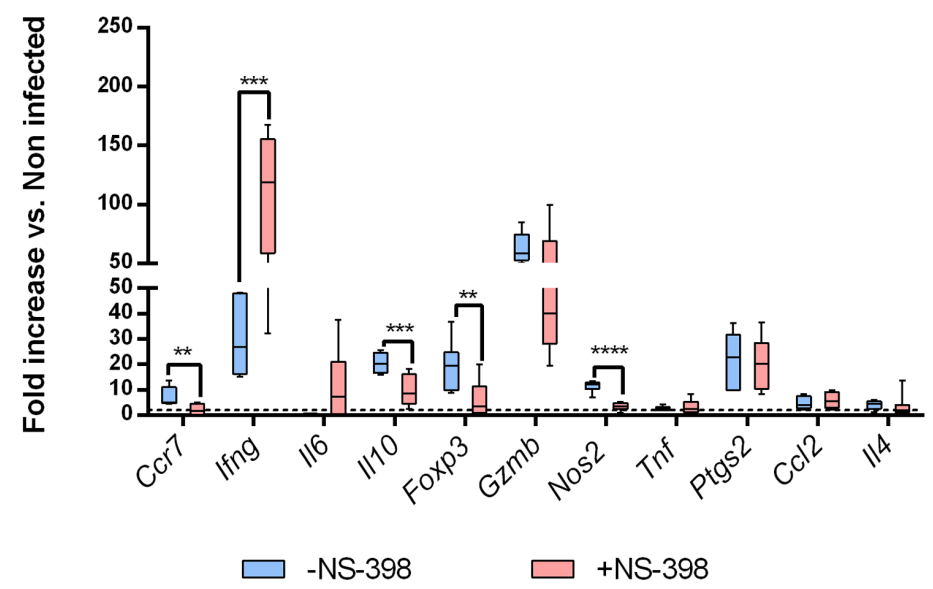

FIGURE 4 | Cyclooxygenase-2 inhibition induces a decrease of bacterial burden in draining lymph nodes. C57BL/6 mice $(n=5)$ were infected with B. melitensis ( $10^{4}$ bacteria per mice) intradermally into ear pinnae. After infection mice received $15 \mathrm{mg} / \mathrm{kg}$ of COX-2 inhibitor (NS-398) or DMSO (mock-treated mice) intraperitoneally daily for 7 days. Data represent two independent experiments. (A) At 8 days post-infection mice were sacrificed and organs were harvested and CLN (Left panel) and spleen (Right panel) were weighted. Statistical significance was determined using ANOVA $(* p<0.05 ; * * * * p<0.0001)$. (B) At 8 days post-infection mice were sacrificed and organs were harvested and analyzed for their CLN (Left panel) or spleen (Right panel) bacterial loads by plating homogenates on nutrient agar. Statistical significance was determined using unpaired, two-tailed Student's $t$-test $(* * p<0.005)$. (C) At 8 days post-infection, total RNA of the CLN was extracted and analyzed for expression of genes involved in inflammatory response by reverse transcription real-time PCR. Results are given as fold increase compared to the signal obtained for mock-infected mice. Statistical significance was determined using unpaired, two-tailed Student's $t$-test $(* * p<0.005$; $\left.{ }^{* * *} p<0.001 ; * * * * 0.0001\right)$. 
Left panel) and no significant response was observed in the spleen (Figure 4B, Right Panel).

The local inflammatory response in NS-398-treated mice was characterized by a strong decrease of $I l 10$ and Nos 2 expression and in a lesser extent of $\mathrm{Ccr} 7$ and Foxp 3 compared to untreated mice. However, Ifng mRNA level strongly increased following NS-398 treatment. All the other genes tested did not exhibit any significant changes in their expression (Figure 4C).

Altogether, these results indicate that inhibition of COX2 decreases bacterial load in CLN by acting on Illo and Ifng expression levels.

\section{DISCUSSION}

In this study, we investigated the impact of Brucella spp. infection on the COX-2 metabolic pathway. We first assessed the ability of B. abortus to stimulate AA production in DC. We also confirmed using a genomic approach that $P G$ pathway downstream partners were overexpressed. We observed that $B$. abortus triggers a higher level of AA in human moDC infected with B. abortus compared to cells infected with other intracellular bacteria (C. burnetii, $T$. whipplei, O. tsutsugamushi). This response was accompanied by an increase of Ptgs 2 mRNA levels in both human and murine DC. Interestingly, we did not detect any major change in the expression profile of the leukotriene pathway and specifically for ALOX5, the gene encoding for the 5-LO in humans. This result is contradictory with previously published data showing that 5LO was strongly up-regulated in Brucella infected spleens as early as one-week post-infection in mice and was accompanied by leukotriene $\mathrm{B}_{4}$ and lipoxin $\mathrm{A}_{4}$ production (Fahel et al., 2015). This discrepancy may be explained by the in vitro DC model used in our study compared to total splenocytes used in the study published in 2015 and also possible differences between the mouse and human models. Moreover, cells expressing 5-LO have not yet been identified in vivo, thus, it could be possible that DC are not the source of leukotrienes during $B$. abortus infection.

Transcriptional profiling showed an increase of PTGER2, PTGER4, and PTGSD expression in infected human moDC compared to unstimulated cells. Interestingly, it has been reported that $\mathrm{PGE}_{2}$ can stimulate IL-10 secretion by mature BMDC leading to a decrease of IL-12 secretion. This effect is dependent on the expression of EP2/EP4 receptors encoded by Ptger2 and Ptger4, respectively (Harizi et al., 2003). Similarly, macrophage treatments with PG analogs stimulating the EP2/EP4 receptors lead to an increase of IL-10 secretion and concomitantly a decrease of TNF- $\alpha$ secretion (Shinomiya et al., 2001). Moreover, in a Pseudomonas aeruginosa intranasal infection model, this immunomodulatory effect towards IL-10 secretion seems to be mediated by EP2 since EP2 ${ }^{-/}$mice presented a lower bacterial burden in the lung (Sadikot et al., 2007). Considering the negative impact of IL-10 on the establishment of a protective immune response during brucellosis, PG pathway could contribute to bacterial persistence.

Then, we determined the levels of expression of Ptgs 2 in vivo using different infection routes. For this purpose, we chose to study physiologically relevant inoculation routes such as nasal, oral, and conjunctival infection routes that mimic natural exposure to bacteria. We also included the intradermal infection route often used for vaccination (Kim et al., 2012). We focused on CLN since CLN also drains the eye (Hamrah and Dana, 2007) and the nasal mucosa (Wolvers et al., 1999) and we previously shown that this organ was preferentially targeted by Brucella after oral inoculation (von Bargen et al., 2014). COX-2 being important during inflammatory process, contrary to the in vitro experiments, we decided to use $B$. melitensis as it seems that this species induced an enhanced inflammation in CLN compared to B. abortus.

As anticipated, we observed a tropism of bacteria for the CLN and a marked lymphadenopathy compared to mock-treated mice as soon as 8 days post-infection in mice infected intradermally and in all conditions at 29 days post-infection. This effect was particularly marked when using the intradermal route. When looking at the local immune response in CLN, we observed that the intradermal route induced a particular gene signature characterized by a strong up-regulation of Ifng and Ptgs 2 mRNA levels compared to the other tested routes. However, we cannot exclude a difference in terms of kinetics due to the fact that intradermal infection delivers directly the bacteria into the tissue. On the contrary, oral, intranasal, and conjunctival inoculations expose bacteria to physiological barriers such as mucosal surfaces that can delay the bacterial trafficking to the draining lymph nodes. Indeed, we observed that at 8 days post-infection bacterial load was significantly higher after intradermal infection but this difference tends to be reduced at later time points. Moreover, using a Yersinia pestis intradermal infection model it has been shown that bacterial dissemination does not involve bacteria active transport through phagocytes to the draining lymph nodes (Gonzalez et al., 2015). At the beginning of the chronic phase (29 days post-infection), we observed a strong decrease of Ifng, Il6, Gzmb concomitant with and an increase of Nos2, Ptgs2 mRNA levels. Interestingly, it has recently been shown that synergic induction of COX- 2 by IFN- $\gamma$ and TNF- $\alpha$ limits type1 immune response in tumor microenvironment by concomitant action of IL-10, NOS2, and Indoleamine 2,3-dioxygenase (Wong et al., 2016). Thus, we can hypothesize that the induction of Ptgs 2 is beneficial for the bacteria.

We then used a specific COX-2 inhibitor (NS-398) and demonstrated the beneficial potential of such an inhibition in favor of the host. Indeed, COX-2 inhibition correlated with a decrease in bacterial load in CLN concomitant with a decrease of Ccr7, Il10, Foxp3, Nos2 mRNA levels and an increase of Ifng expression. At early time points, the induction of Ptgs 2 gene expression could be used by the bacteria to stimulate not only their replication but also the migration of the infected cells to other secondary organs as suggested by the effect on $\mathrm{Ccr} 7$ expression. It is also known that Th1 immune response characterized by IFN- $\gamma$ and IL-12 secretion is important to control infection and that production of IL-10 has a negative impact in the course of brucellosis control by the host (Zhan and Cheers, 1995; Brandao et al., 2012). Then, we can hypothesize that the beneficial effect observed in the presence of COX-2 inhibitor treatment can be associated with a strong Th1 response. Moreover, it has been demonstrated that in absence of IL-10, 
mice are more resistant to Brucella infection and this effect is correlated with an increase of pro-inflammatory cytokine secretion (Corsetti et al., 2013). The decrease of Ill0 mRNA levels is also accompanied by a decrease of Foxp3 expression, a marker of regulatory T lymphocytes (T-reg). After intraperitoneal infection, it has been shown that $\mathrm{CD} 4^{+} \mathrm{CD} 25^{+} \mathrm{T}$ cells produce IL-10 during acute brucellosis that favor bacterial persistence in mice (Xavier et al., 2013). $\mathrm{CD}^{+} \mathrm{CD} 25^{+} \mathrm{T}$ cell population in parotid and retropharyngeal lymph nodes has been shown to increase following conjunctival infection in sheep (Suraud et al., 2007). CD $4^{+} \mathrm{CD} 25^{+} \mathrm{T}$ cells with regulatory activity express the transcription factor Foxp3 (Hori et al., 2003). Interestingly, following NS-398 treatment, we observed a significant decrease of Foxp3 expression. This finding is in accordance with the decrease of Il10 expression. Thus, we hypothesize that infection stimulates regulatory/suppressor T-cells that can favor bacterial persistence through the secretion of IL-10. A similar effect has been described during Mycobacterium tuberculosis infection where COX-2/PGE 2 axis stimulates T-reg expansion (Garg et al., 2008; Holla et al., 2016). Thereby, T-reg accumulation contributes to the decrease of bacterial clearance in infected mice (Kursar et al., 2007). During Francisella tularensis live vaccine strain intranasal infection, the inhibition of the COX-1 and COX-2 increased the number of IFN- $\gamma$ producing $\mathrm{T}$ lymphocytes in the lung leading to a decrease of the bacterial load (Woolard et al., 2008). This is correlated with our observations showing that COX-2 inhibition leads to an increase of Ifng mRNA levels in CLN.

Our results corroborate other studies which have investigated the involvement of the COX-2 pathway during bacterial infection by Pseudomonas aeruginosa (Sadikot et al., 2007), Burkholderia pseudomallei (Asakrah et al., 2013), and Streptococcus pyogenes (Goldmann et al., 2010). COX-2 inhibition translates into a decrease of bacterial burden in CLN. It would be interesting to look at later time points to know whether or not COX-2 inhibition can cause a bacterial clearance. Taken together, our results suggest that Brucella has taken advantage of the PG pathway to survive and replicate in host cells and that COX-2 inhibition is not only crucial to control brucellosis but also other bacterial infectious diseases.

\section{REFERENCES}

Agard, M., Asakrah, S., and Morici, L. A. (2013). PGE(2) suppression of innate immunity during mucosal bacterial infection. Front. Cell. Infect. Microbiol. 3:45. doi: $10.3389 /$ fcimb.2013.00045

Asakrah, S., Nieves, W., Mahdi, Z., Agard, M., Zea, A. H., Roy, C. J., et al. (2013). Post-exposure therapeutic efficacy of COX-2 inhibition against Burkholderia pseudomallei. PLoS Negl. Trop. Dis. 7:e2212. doi: 10.1371/journal.pntd.0002212

Barquero-Calvo, E., Chaves-Olarte, E., Weiss, D. S., Guzmán-Verri, C., ChacónDíaz, C., Rucavado, A., et al. (2007). Brucella abortus uses a stealthy strategy to avoid activation of the innate immune system during the onset of infection. PLoS ONE 2:e631. doi: 10.1371/journal.pone.0000631

Barry, A. O., Boucherit, N., Mottola, G., Vadovic, P., Trouplin, V., Soubeyran, P., et al. (2012). Impaired stimulation of p38 $\alpha$-MAPK/Vps41-HOPS by LPS from pathogenic Coxiella burnetii prevents trafficking to microbicidal phagolysosomes. Cell Host Microbe 12, 751-763. doi: 10.1016/j.chom.2012. 10.015

\section{AUTHOR CONTRIBUTIONS}

AG, J-PG, and J-LM conceived and designed the experiments. AG, LG, AP, and KVB performed the experiments. AG, LG, and J-PG analyzed the data. AG and J-PG wrote the paper.

\section{FUNDING}

J-PG was financed by an institutional grant from the Centre National de la Recherche Scientifique for equipment, consommables, and salary, by an institutional grant from the Institut National de la Santé et de la Recherche Médicale for equipment and consommables and by the grant $n^{\circ}$ CS2012-2016 from the Fondation pour la Recherche Médicale, for equipment and consommables. AG and AP were financed by a fellowship from the Aix Marseille Université. J-LM was financed by the Assistance Publique des hôpitaux de Marseille for ressources and salary. J-PG and KVB were financed by the Agence National de la Recherche, grant $\mathrm{n}^{\circ} \mathrm{ANR} 10$-BLAN-000 for ressources and salary, respectively.

\section{ACKNOWLEDGMENTS}

The authors would like to thank Hugues Lelouard, Johnny Bonnardel, and Clara Degos for providing and supporting in establishment of protocols and for valuable discussions. We deeply thank Dr. Ignacio Moriyon for providing the Brucella strains as well as Dr. Philippe Pierre for the J558L GM-CSF producing cell line. Also, we are very grateful to the BSL-3 core facilities staff at the Immunophenomique Center (CIPHE).

\section{SUPPLEMENTARY MATERIAL}

The Supplementary Material for this article can be found online at: http://journal.frontiersin.org/article/10.3389/fmicb. 2016.01987/full\#supplementary-material

Bowman, C. C., and Bost, K. L. (2004). Cyclooxygenase-2-mediated prostaglandin E2 production in mesenteric lymph nodes and in cultured macrophages and dendritic cells after infection with Salmonella. J. Immunol. 172, 2469-2475. doi: 10.4049/jimmunol.172.4.2469

Brandao, A. P., Oliveira, F. S., Carvalho, N. B., Vieira, L. Q., Azevedo, V., Macedo, G. C., et al. (2012). Host susceptibility to Brucella abortus infection is more pronounced in IFN-gamma knockout than IL-12/beta2-microglobulin doubledeficient mice. Clin. Dev. Immunol. 2012:589494. doi: 10.1155/2012/589494

Chandrasekharan, N. V., Dai, H., Roos, K. L., Evanson, N. K., Tomsik, J., Elton, T. S., et al. (2002). COX-3, a cyclooxygenase-1 variant inhibited by acetaminophen and other analgesic/antipyretic drugs: cloning, structure, and expression. Proc. Natl. Acad. Sci. U.S.A. 99, 13926-13931. doi: 10.1073/pnas. 162468699

Chandrasekharan, N. V., and Simmons, D. L. (2004). The cyclooxygenases. Genome Biol. 5:241. doi: 10.1186/gb-2004-5-9-241

Conde-Álvarez, R., Arce-Gorvel, V., Iriarte, M., Manček-Keber, M., BarqueroCalvo, E., Palacios-Chaves, L., et al. (2012). The lipopolysaccharide core of 
Brucella abortus acts as a shield against innate immunity recognition. PLoS Pathog. 8:e1002675. doi: 10.1371/journal.ppat.1002675

Corsetti, P. P., de Almeida, L. A., Carvalho, N. B., Azevedo, V., Silva, T. M., Teixeira, H. C., et al. (2013). Lack of endogenous IL-10 enhances production of proinflammatory cytokines and leads to Brucella abortus clearance in mice. PLoS ONE 8:e74729. doi: 10.1371/journal.pone.0074729

Dean, A. S., Crump, L., Greter, H., Hattendorf, J., Schelling, E., and Zinsstag, J. (2012). Clinical manifestations of human brucellosis: a systematic review and meta-analysis. PLoS Negl. Trop. Dis. 6:e1929. doi: 10.1371/journal.pntd. 0001929

Ecker, J., Scherer, M., Schmitz, G., and Liebisch, G. (2012). A rapid GC-MS method for quantification of positional and geometric isomers of fatty acid methyl esters. J. Chromatogr. B Analyt. Technol. Biomed. Life Sci. 897, 98-104. doi: 10.1016/j.jchromb.2012.04.015

Fahel, J. S., de Souza, M. B., Gomes, M. T., Corsetti, P. P., Carvalho, N. B., Marinho, F. A., et al. (2015). 5-Lipoxygenase negatively regulates Th1 response during Brucella abortus infection in mice. Infect. Immun. 83, 1210-1216. doi: 10.1128/ IAI.02592-14

Franco, M. P., Mulder, M., Gilman, R. H., and Smits, H. L. (2007). Human brucellosis. Lancet Infect. Dis. 7, 775-786. doi: 10.1016/S1473-3099(07)70286-4

Garg, A., Barnes, P. F., Roy, S., Quiroga, M. F., Wu, S., García, V. E., et al. (2008). Mannose-capped lipoarabinomannan- and prostaglandin E2dependent expansion of regulatory $\mathrm{T}$ cells in human Mycobacterium tuberculosis infection. Eur. J. Immunol. 38, 459-469. doi: 10.1002/eji.200737268

Goldmann, O., Hertzén, E., Hecht, A., Schmidt, H., Lehne, S., Norrby-Teglund, A., et al. (2010). Inducible cyclooxygenase released prostaglandin E2 modulates the severity of infection caused by Streptococcus pyogenes. J. Immunol. 185, 2372-2381. doi: 10.4049/jimmunol.1000838

Gonzalez, R. J., Lane, M. C., Wagner, N. J., Weening, E. H., and Miller, V. L. (2015). Dissemination of a highly virulent pathogen: tracking the early events that define infection. PLoS Pathog. 11:e1004587. doi: 10.1371/journal.ppat. 1004587

Gorvel, L., Al Moussawi, K., Ghigo, E., Capo, C., Mege, J. L., and Desnues, B. (2010). Tropheryma whipplei, the Whipple's disease bacillus, induces macrophage apoptosis through the extrinsic pathway. Cell Death Dis. 1:e34. doi: $10.1038 /$ cddis. 2010.11

Grilló, M. J., Blasco, J. M., Gorvel, J. P., Moriyón, I., and Moreno, E. (2012). What have we learned from brucellosis in the mouse model? Vet. Res. 43, 29. doi: 10.1186/1297-9716-43-29

Hamrah, P., and Dana, M. R. (2007). Corneal antigen-presenting cells. Chem. Immunol. Allergy 92, 58-70. doi: 10.1159/000099254

Harizi, H., Corcuff, J. B., and Gualde, N. (2008). Arachidonic-acid-derived eicosanoids: roles in biology and immunopathology. Trends Mol. Med. 14, 461-469. doi: 10.1016/j.molmed.2008.08.005

Harizi, H., Grosset, C., and Gualde, N. (2003). Prostaglandin E2 modulates dendritic cell function via EP2 and EP4 receptor subtypes. J. Leukoc. Biol. 73, 756-763. doi: 10.1189/jlb.1002483

Holla, S., Stephen-Victor, E., Prakhar, P., Sharma, M., Saha, C., Udupa, V., et al. (2016). Mycobacteria-responsive sonic hedgehog signaling mediates programmed death-ligand 1- and prostaglandin E2-induced regulatory T cell expansion. Sci. Rep. 6:24193. doi: 10.1038/srep24193

Hori, S., Nomura, T., and Sakaguchi, S. (2003). Control of regulatory T cell development by the transcription factor Foxp3. Science 14, 1057-1061.

Kim, Y. C., Jarrahian, C., Zehrung, D., Mitragotri, S., and Prausnitz, M. R. (2012). Delivery systems for intradermal vaccination. Curr. Top. Microbiol. Immunol. 351, 77-112. doi: 10.1007/82_2011_123

Kursar, M., Koch, M., Mittrücker, H. W., Nouailles, G., Bonhagen, K., Kamradt, T., et al. (2007). Cutting edge: regulatory $\mathrm{T}$ cells prevent efficient clearance of Mycobacterium tuberculosis. J. Immunol. 178, 2661-2665. doi: 10.4049/ jimmunol.178.5.2661

Lapaque, N., Moriyon, I., Moreno, E., and Gorvel, J. P. (2005). Brucella lipopolysaccharide acts as a virulence factor. Curr. Opin. Microbiol. 8, 60-66. doi: 10.1016/j.mib.2004.12.003

Lapaque, N., Muller, A., Alexopoulou, L., Howard, J. C., and Gorvel, J. P. (2009). Brucella abortus induces Irgm 3 and Irga6 expression via type-I IFN by a MyD88-dependent pathway, without the requirement of TLR2. TLR4, TLR5 and TLR9. Microb. Pathog. 47, 299-304. doi: 10.1016/j.micpath.2009. 09.005
Lepage, G., and Roy, C. C. (1986). Direct transesterification of all classes of lipids in a one-step reaction. J. Lipid Res. 27, 114-120.

López-Urrutia, L., Alonso, A., Bayón, Y., Nieto, M. L., Orduña, A., and Sánchez Crespo, M. (2001). Brucella lipopolysaccharides induce cyclooxygenase-2 expression in monocytic cells. Biochem. Biophys. Res. Commun. 289, 372-375. doi: 10.1006/bbrc.2001.5995

Martirosyan, A., Moreno, E., and Gorvel, J. P. (2011). An evolutionary strategy for a stealthy intracellular Brucella pathogen. Immunol. Rev. 240, 211-234. doi: 10.1111/j.1600-065X.2010.00982.x

Moreno, E. (2014). Retrospective and prospective perspectives on zoonotic brucellosis. Front. Microbiol. 5:213. doi: 10.3389/fmicb.2014.00213

Papadopoulos, A., Gagnaire, A., Degos, C., de Chastellier, C., and Gorvel, J. P. (2016). Brucella discriminates between mouse dendritic cell subsets upon in vitro infection. Virulence 7, 33-44. doi: 10.1080/21505594.2015.1108516

Pappas, G. (2010). The changing Brucella ecology: novel reservoirs, new threats. Int. J. Antimicrob. Agents 36(Suppl. 1), S8-S11. doi: 10.1016/j.ijantimicag.2010. 06.013

Pizarro-Cerdá, J., Méresse, S., Parton, R. G., van der Goot, G., Sola-Landa, A., Lopez-Goñi, I., et al. (1998). Brucella abortus transits through the autophagic pathway and replicates in the endoplasmic reticulum of nonprofessional phagocytes. Infect. Immun. 66, 5711-5724.

Rangel Moreno, J., Estrada García, I., De La Luz García Hernández, M., Aguilar Leon, D., Marquez, R., and Hernández Pando, R. (2002). The role of prostaglandin E2 in the immunopathogenesis of experimental pulmonary tuberculosis. Immunology 106, 257-266. doi: 10.1046/j.1365-2567.2002.01403.x

Sadikot, R. T., Zeng, H., Azim, A. C., Joo, M., Dey, S. K., Breyer, R. M., et al. (2007). Bacterial clearance of Pseudomonas aeruginosa is enhanced by the inhibition of COX-2. Eur. J. Immunol. 37, 1001-1009. doi: 10.1002/eji.200636636

Salcedo, S. P., Marchesini, M. I., Lelouard, H., Fugier, E., Jolly, G., Balor, S., et al. (2008). Brucella control of dendritic cell maturation is dependent on the TIR-containing protein Btp1. PLoS Pathog. 4:e21. doi: 10.1371/journal.ppat. 0040021

Schutter, M. E., and Dick, R. P. (2000). Comparison of fatty acid methyl ester (FAME) methods for characterizing microbial communities. Soil Sci. Soc. Am. J. 64, 1659-1668. doi: 10.2136/sssaj2000.6451659x

Seleem, M. N., Boyle, S. M., and Sriranganathan, N. (2010). Brucellosis: a reemerging zoonosis. Vet. Microbiol. 140, 392-398. doi: 10.1016/j.vetmic.2009. 06.021

Shinomiya, S., Naraba, H., Ueno, A., Utsunomiya, I., Maruyama, T., Ohuchida, S., et al. (2001). Regulation of TNFalpha and interleukin-10 production by prostaglandins $\mathrm{I}(2)$ and $\mathrm{E}(2)$ : studies with prostaglandin receptordeficient mice and prostaglandin E-receptor subtype-selective synthetic agonists. Biochem. Pharmacol. 61, 1153-1160. doi: 10.1016/S0006-2952(01) 00586-X

Steer, S. A., and Corbett, J. A. (2003). The role and regulation of COX-2 during viral infection. Viral Immunol. 16, 447-460. doi: 10.1089/0882824037719 26283

Stevens, M. G., and Olsen, S. C. (1994). In vitro effects of live and killed Brucella abortus on bovine cytokine and prostaglandin E2 production. Vet. Immunol. Immunopathol. 40, 149-161. doi: 10.1016/0165-2427(94) 90030-2

Suraud, V., Olivier, M., Bodier, C. C., and Guilloteau, L. A. (2007). Differential expression of homing receptors and vascular addressins in tonsils and draining lymph nodes: effect of Brucella infection in sheep. Vet. Immunol. Immunopathol. 15, 239-250. doi: 10.1016/j.vetimm.2006.11.008

Van den Broeck, W., Derore, A., and Simoens, P. (2006). Anatomy and nomenclature of murine lymph nodes: descriptive study and nomenclatory standardization in BALB/cAnNCrl mice. J. Immunol. Methods 30, 12-19. doi: 10.1016/j.jim.2006.01.022

von Bargen, K., Gagnaire, A., Arce-Gorvel, V., de Bovis, B., Baudimont, F., Chasson, L., et al. (2014). Cervical lymph nodes as a selective niche for Brucella during oral infections. PLOS ONE 10:e0121790. doi: 10.1371/journal.pone. 0121790

Wolvers, D. A., Coenen-de Roo, C. J., Mebius, R. E., van der Cammen, M. J., Tirion, F., Miltenburg, A. M., et al. (1999). Intranasally induced immunological tolerance is determined by characteristics of the draining lymph nodes: studies with OVA and human cartilage gp-39. J. Immunol. 15, 1994-1998. 
Wong, J. L., Obermajer, N., Odunsi, K., Edwards, R. P., and Kalinski, P. (2016). Synergistic COX2 Induction by IFNgamma and TNFalpha Self-Limits Type-1 immunity in the human tumor microenvironment. Cancer Immunol. Res. 4, 303-311. doi: 10.1158/2326-6066.CIR-15-0157

Woolard, M. D., Hensley, L. L., Kawula, T. H., and Frelinger, J. A. (2008). Respiratory Francisella tularensis live vaccine strain infection induces Th17 cells and prostaglandin E2, which inhibits generation of gamma interferon-positive T cells. Infect. Immun. 76, 2651-2659. doi: 10.1128/IAI. 01412-07

Xavier, M. N., Winter, M. G., Spees, A. M., Nguyen, K., Atluri, V. L., Silva, T. M., et al. (2013). CD4+ T cell-derived IL-10 promotes Brucella abortus persistence via modulation of macrophage function. PLoS Pathog. 9:e1003454. doi: 10.1371/journal.ppat.1003454

Zhan, Y., and Cheers, C. (1995). Endogenous interleukin-12 is involved in resistance to Brucella abortus infection. Infect. Immun. 63, 1387-1390.
Zhan, Y., Liu, Z., and Cheers, C. (1996). Tumor necrosis factor alpha and interleukin-12 contribute to resistance to the intracellular bacterium Brucella abortus by different mechanisms. Infect. Immun. 64, 2782-2786.

Conflict of Interest Statement: The authors declare that the research was conducted in the absence of any commercial or financial relationships that could be construed as a potential conflict of interest.

Copyright (c) 2016 Gagnaire, Gorvel, Papadopoulos, Von Bargen, Mège and Gorvel. This is an open-access article distributed under the terms of the Creative Commons Attribution License (CC BY). The use, distribution or reproduction in other forums is permitted, provided the original author(s) or licensor are credited and that the original publication in this journal is cited, in accordance with accepted academic practice. No use, distribution or reproduction is permitted which does not comply with these terms. 